\title{
Participatory Technology and Constraints Assessment to Improve the Livelihood of Beekeepers in Tigray Region, northern Ethiopia
}

\section{Gidey Yirga* and Mekonen Teferi}

Biology Department, College of Natural and Computational Sciences, P.O. Box 3072, Mekelle University Mekelle Ethiopia (*gidey1998ec@yahoo.com)

\begin{abstract}
Beekeeping is a long-standing practice in the rural communities of Ethiopia and appears as ancient history of the country. A three-part assessment and diagnostic study (Livelihood systems assessment, integrated honeybee management needs assessment and diagnostic survey) was undertaken from 2006-2008 in Tigray, Ethiopia to identify market and technological constraints facing the honey sub sector and asses bee pests and the control measures taken. Information was gathered through PRA, interview with key informants and integrated honeybee management diagnostic survey in the rural areas. The assessment and diagnostic activities were undertaken in six zones (Western, North western, Central, Eastern, Southern and Southeastern zones of the region). One hundred nineteen beekeepers were randomly selected. Information on the adoption of new technology, availability of honeybee pests, average annual harvest of honey, honeybee pest controlling measures, market and technological constraints etc. were sought from the beekeepers. Honey yield was markedly different for the traditional and modern hives. On average, it was about 8-15 kg/hive and 20-30 kg/hive from the traditional and modern hives respectively. Lack of adequate bee forages, poor market, lack of trained development agents, inadequate government support, bee pests and inadequate training are mainly the problems facing the honey sub sector in the region. There are different kinds of bee pests and predators. Honey is harvested twice a year. From this study it was realized that almost all beekeeping practices are traditional except little intervention with improved beekeeping practices.
\end{abstract}

Key words: Beekeeping, Bee management, Beehive, Tigray.

\section{INTRODUCTION}

Beekeeping is a long-standing practice in the rural communities of Ethiopia and appears as an ancient history of the country (Ayalew and Gezahegn, 1991). Beekeeping is an environmentally friendly and non-farm business activity that has immense contribution to the economies of the society and to a national economy as whole. Ethiopia has a huge natural resource base for honey production and other hive products, and beekeeping is traditionally a well established household activity in almost all parts of the country. However, the benefit from the sub sector to the nation as well as to the farmers, traders, processors and exporter is not satisfactory (Beyene and David, 2007).

Beekeeping as a business is a resent development in Ethiopia. Presently, honey is highly commercialized and its market surplus accounts for over 90 per cent of the total harvest. The 
large portion (70 per cent) of the marketed honey goes to the production of Tej (beverage) and only around 30 per cent is used as a table honey. Moreover, the volume of export in both honey and beeswax products has notably declined since the last decade. This is largely attributed to the deterioration in quality of the products, EU (European Union) restriction and increasing demand in the domestic market (Beyene and David, 2007). The total honey production of Ethiopia is estimated up to 24000 metric tones; only a small amount of this is marketed. Besides poor marketing conditions the main reason is that about 80 per cent of the total Ethiopian honey production goes in to the local Tej-preparation, a honey wine, which consumed as national drink in large quantities (Hartmann, 2004).

In Ethiopia, beekeeping is a promising non-farm activity for the rural households. It contributes to the incomes of households and the economy of the nation. The direct contribution of beekeeping includes the value of the outputs produced such as honey, bee wax, queen and bee colonies, and other products such as pollen, royal jelly, bee venom, and propolis in cosmetics and medicine (ARSD, 2000 and Gezahegn, 2001). It also provides an employment opportunity in the sector. The exact number of people engaged in the honey sub-sector in Ethiopia is not well known. However, it is estimated that around one million farm households are involved in beekeeping business using the traditional, intermediate and modern hives. It could also be observed that a large number of people (intermediaries and traders) participate in honey collection and retailing (at village, district and zonal levels). Thousands of households are engaged in Tej-making in almost all urban areas, hundreds of processors are emerging and exporters are also flourishing (Beyene and David, 2007). Honey and beeswax also play a big role in the cultural and religious life of the people of Ethiopia.

Another very important contribution of beekeeping is through plant pollination and conservation of the natural environment. Beekeeping is environmentally sustainable activity that can be integrated with agricultural practices like crop production, animal husbandry, horticultural crops and conservation of natural resources. Thus, it would be one of the most important intervention areas for sustainable development of poor countries like Ethiopia (Gibbon, 2001). The contributions of beekeeping in poverty reduction, sustainable development and conservation of natural resources have been well recognized and emphasized by the government of Ethiopia and non-governmental organizations (NGOs). As the country is endowed with varied ecological zones and different flora, it has a huge potential for beekeeping. However, the roles of 
beekeeping as income generation or diversification for subsistence farmers and generating foreign exchange earnings have been very minimal.

Plentiful forage availability coupled with favourable and diversified agro-climatic conditions of Ethiopia create environmental conditions conducive for the growth of over 7000 species of flowering plants which has supported the existence of large number of local bee colonies in Ethiopia. It is estimated that over two million bee-colonies in the countries exists in the forest and crevices. The density of hives occupied by the honeybees on the land may be the highest, at the present moment, of any country in the African continent (Ayalew and Gezahegn, 1991). Ethiopia's wide climatic and edaphic variability have endowed this country with diverse and unique flowering plants, thus making it highly suitable for sustaining a large number of bee colonies and the long established practice of beekeeping. Nevertheless, the bees and the plants they depend on, like all renewable natural resources, are constantly under threat from lack of knowledge and appreciation of these endowments (Girma, 1998).

In general, the potential areas for honey and beeswax production in the country include Southwestern, Western and North-western parts of the country (ARSD, 2000 and Gezahegn, 2001). These are grouped into high, medium and low potential areas. Many of the districts in Tigray, Wollo and Hararege and in some other parts of the country which are covered with marginal forests do have relatively low potential in honey production (Beyene and David, 2007). The principal resource base for beekeeping has, however, become seriously degraded in the course of time. The potential of the Ethiopian landscape for honey and wax production does now, undoubtedly, only constitute a small fraction of its former wealth. Moreover, the destruction of the remaining resource-base can be observed going on at a steadily accelerating pace (Girma, 1998).

Based on the level of technological advancement three types of beehives are used for honey production in Ethiopia. These are traditional, intermediate, and modern hives. A total of about 4,601,806 hives exist in the country of which about 95.5 per cent are traditional, 4.3 per cent transitional and 0.20 per cent modern hives (Beyene and David, 2007). The traditional beekeeping accounts for more than 95 per cent of the honey and beeswax produced in the country. In Ethiopia, honey has long tradition and cultural values, for instance as a gift in dowries during marriage, as an important ingredient for processing honey wine locally called Tej 
brewery and beeswax is used to produce light particularly in the Orthodox churches (Beyene and David, 2007).

In Ethiopia, beekeeping is an integral part of the life style of the farming communities, and except for a few extreme areas, it is a common practice in every place where humankind has settled. In addition, Ethiopia has probably the longest tradition of all the African counties in beeswax and honey marketing. The time is immemorial as to when and where marketing of honey and beeswax has been started in the country (Beyene and David, 2007).

The national average honey produced for the year 1997 to 2004 was estimated at 30 thousand metric tones, which accounted over 23 per cent of the total African production and about 2 per cent of world honey production (MoARD, 2005). Production of beeswax was three thousand tons per annum placing the country among the four largest world beeswax producers (Ibid, 2005).

In the country, it is estimated that around one million farmer households participate in beekeeping. Honey is produced mainly as a cash crop, which is serving as a source of additional cash income for hundreds of thousands of farmer beekeepers. Honey is mainly produced for market. More than 95 per cent of the total produced is marketed, while the remaining is used for home consumption. In addition, a significant number of people are engaged in production and trading of honey at different levels and selling of honey wines (local beverage Tej) which create job and self-employment opportunities for large number of citizens. Export of honey and bee wax is estimated to contribute an average of 1.6 million USD to the annual national export earnings (Ethiopian Customs Authority and Export Promotion Agency, 2006).

Many factors are pointed out as causes for unemployment in rural areas of Ethiopia. The commonly mentioned ones are drought; sever physical environmental degradations, very low levels of investment in the agricultural and non agricultural sectors, lack of non-farm employment activities, lack of skills and adequate initial capital to run income generating activities and poor rural-urban linkages.

Although the annual production of both honey and wax in Ethiopia is large compared to other African countries, the system of production commonly exercised in the country is traditional. Productivity of honeybees is very low and only an average of 8-15kg of honey could be cropped per hive per year. However, in areas where improved technology has been introduced, an average of 15-20 kg/hive/year has been recorded. Ethiopia, having the highest number of bee 
colonies and surplus honey sources of flora, is the leading producer of honey and beeswax in Africa. On a world level, Ethiopia is fourth in beeswax and tenth in honey production (Ayalew and Gezehegn, 1991).

In Tigray Region, northern Ethiopia, apiculture is a good source of income for smallholder farmers, as both honey and bee colonies are in high demand. To increase the yield and improve the quality of honeybee resources in the region, the Tigray Government introduced modern (Kenya top-bar) beehives and accessories. However, because this equipment is relatively expensive to buy, most smallholders could not increase their income as had been expected. Some innovative beekeepers started to use alternative equipment and practices to manage their bee resources and to improve the quality of the products (Hailu et al., 2007). The theme of this investigation was to examine the technological constraints, honeybee pests and their management, and asses the production systems under practice.

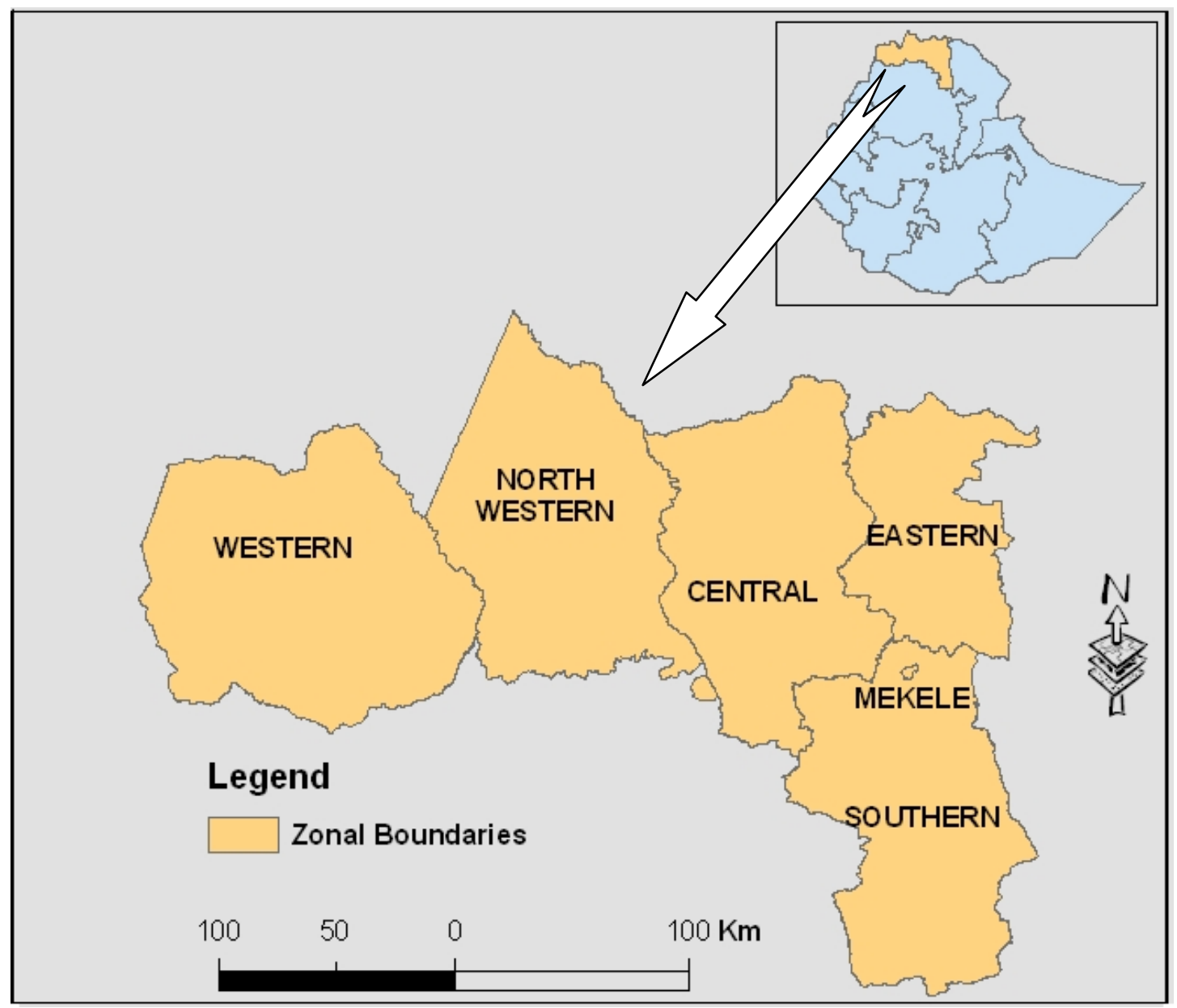

Figure 1. Map of Tigray showing the different sampled zones. 


\section{MATERIALS AND METHODS}

\subsection{Study area}

The study area, Tigray, is the Northern most region of Ethiopia located on the Sudano-Sahelian dry land zone. It covers an approximate area of 50 thousand square kilometer with an average population density of about 65 persons $/ \mathrm{km}^{2}$ and population growth rate of about 3 per cent. Most of the area is arid or semi-arid with annual precipitation of 450-980 mm. Mostly the rain falls within the months of June, July and August, exhibiting high intensity and high temporal and spatial variability (Berhanu, 1998). More than 85 per cent of the regional population lives in the rural areas and depends on mixed crop-livestock subsistence agriculture.

\subsection{Assessment and Diagnosis}

A three-part assessment and diagnostic study was undertaken focusing on:

1)The honeybee production and beekeepers livelihood system

2)Honeybee production needs and problems, and

3)Pests affecting honeybee production and their management practices.

This phase combined a macro-level analysis for understanding the dynamics of the overall Integrated Honeybee Management (IHBM) livelihood system, with a micro-level analysis to identify specific technological needs and opportunities for honeybee production, particularly integrated pest management in honeybee.

Results of the livelihood systems assessment were used to identify whether honeybee production is a major source of cash income supporting the livelihood of a wide range of households/groups -bee keepers, traders and honey and wax processors. The results were also used to look for key technological and market constraints affecting honeybee production system. The assessment was used in the identification of windows of opportunities for Participatory Technology Development (PTD) seeking to address technological constraints: incidence of pest and disease complex, quality of honey products and limited technological knowledge of the bee keepers. While nontechnological in nature, market-related constraints were likewise addressed in subsequent phases by developing capacity of farming households to cope with the dynamics of markets and prices. Questionnaires were developed and administered to one hundred nine-teen randomly selected beekeepers in all zones of Tigray to obtain data related to market and technological constraints, government support for the honeybees sub sector, bee pest management, adopted technologies etc. The researches' direct observation of the area has also generated some data. Key informant 
interviews were carried out to obtain information on the honeybee pests, pest management under practice, introduced technologies etc. The informants included Community Elders, Extension workers working at the study sites and Peasant Administration (PA) Officials. Focused group discussions were held in study communities. The participants were representatives from different farmers, from various Kushets, from different economic strata and from both sexes to maintain gender balance. The participants expressed their own feelings (perceptions), and offered their experiences regarding the issues under study.

\section{RESULTS AND DISCUSSION}

\subsection{Honey marketing and quality}

45.7 per cent of the bee keepers households responded "Yes" for the question "is bee keeping a major source of cash income supporting the family livelihood ?” and the majority (54.3 per cent) "No". This suggests that beekeeping is not a major source of cash income for many of the farmers but as a supportive income to meet their demand for cash to pay debts and for their living conditions. There was variation in the amount of money earned. The results also showed that the amount of money earned per year was generally low or too little to sustain the needs of the households. Coupled with the low local demand for honey, the respondents noted that the income from honey production is unsteady. Beekeepers sell the largest proportion of their honey during harvest at low price to meet their demand for cash to pay taxes, debts and other social obligations (Beyene and David, 2007). The market for honey is generally poor, mainly due to a limited number of buyers, poor market infrastructure and poor market information. According to the households large quantities of honey are supplied to Tej houses in their areas. Another problem of the respondents was related to the production, pricing and marketing of honey.

The beekeepers noted that the amount of honey harvested tends to fall below their expectations. Prices offered for their honey are generally low. Bees and Beekeeping contributes to sustainable rural livelihoods not only through production and sale of honey and its bi-products, but also through maintenance of biodiversity and increase in crop production through bees pollinating services. In terms of nutritional and economic benefit to people, the role of bees in crop pollination is even more important than their role as producers of honey and other products. In the absence of pollinators mainly honey bees, vegetable and seed crops and tree crops yield loss was estimated to be 26 and 43 per cent, respectively (Buchmann and Nabham, 1995). Bees are 
essential components of every ecosystem, maintaining biodiversity through pollination, and honey production is therefore highly sustainable.

Of the total beekeeping households interviewed, majority (72.3 per cent) (Table 1) responded poor quality for the question "how do you classify the quality of honeybee products? Good quality honey was harvested from modern hives and poor from the traditional ones. They produce a low quality product that they are forced to sell locally to wholesale buyers at prices much lower than in domestic commercial markets. This poor quality of honey is probably attributed to the bee forages and bee management practices. Majority of the production practice are still very traditional and results in poor quality and quantity of honey. The type of hives used the methods of removing and storage of honey play a vital role in the quality of honey (Crane, 1970, as cited by Edessa Negera, 2005). The knowledge and skill of honey production and honey and beeswax extraction of Ethiopian farmers is still very traditional (MoARD, 2006). Low productivity and poor quality of bee products are the major economic impediments for rural beekeepers (Nuru, 1999).

The total honey production of Ethiopia is estimated up to 24000 metric tones; only a small amount of this is marketed. Besides poor marketing conditions the main reason is that about 80 per cent of the total Ethiopian honey production goes in to the local Tej-preparation, a honey wine, which consumed as national drink in large quantities (Hartmann, 2004). Even though honey satisfies the local demand, it is so crude that it cannot compete in the international market (Ministry of Trade and Industry, 1995). Export of honey and beeswax is estimated to contribute an average of USD 1.6 million to the annual national export earnings (EEPD, 2006).

\begin{tabular}{|lll|}
\hline $\begin{array}{r}\text { Table } 1 \text { Response of households for the question "how do you classify the } \\
\text { quality of honeybee products? }\end{array}$ \\
\hline Response & Number of respondents & Percentage \\
\hline Good quality & 33 & 27.7 \\
\hline Poor quality & 86 & 72.3 \\
\hline Total & 119 & 100.00 \\
\hline
\end{tabular}

They were also asked, "Are you aware that Ethiopia is one of the major exporters of honey in the world? Ethiopia is fourth in beeswax and tenth in honey production. 99 per cent responded "No" indicating that they do not realize that their country Ethiopia is rich in honeybee and wax 
production. Only one per cent of the respondents responded "Yes" indicating that they were aware that Ethiopia is a leading producer of honey in Africa.

\subsection{Honey yield, production practices and Honey bee flora}

Honey yield was markedly different for the traditional and modern hives. On average, it was about 8-15 kg/hive and 20-30 kg/hive from the traditional and modern hives respectively. High variability in yield was observed within the farmers. This is most probably due to differences in management of bees, and from exogenous factors such as climate changes, pests and diseases.There is a significant difference between the mean yield obtained annually between the traditional and modern hives. Even though apiculture presents an opportunity for small producers, for many beekeepers the potential to create a significant livelihood from selling honey remains out of reach. Honey is produced at house hold level by beekeepers. Harvesting is conducted ones or twice a year. This is probably attributed to the natural flora of the localities. As is the case in many other areas of the country, beekeeping in Tigray is also mainly based on traditional systems.

In Tigray land degradation and removal of vegetation cover are very high. The principal bee flora for beekeeping has become seriously degraded in the course of time. The bees and the plants they depend on, like all renewable natural resources, are constantly under threat from lack of knowledge and appreciation of these endowments (Girma, 1998). Yet, despite such big challenges, there are a wide variety of plants which are used as honeybee flora. In some areas there is active planting of nectar yielding vegetation. In some places the beekeepers themselves have endeavoured to redress the situation by planting good honey plants near their hive colonies. Despite such local improvements, which in some places are spectacular, the bee-keeping resource base is still deteriorating in some areas. The interviewed beekeepers responded that Eucalyptus trees, herbs, weeds, cultivated crops, shrubs, and some woody plants are the main honey sources.

\subsection{Adoption of technologies}

Great effort has been made by government extension package and Relief Society of Tigray (REST) to adopt movable frame hive technology to the region to increase quantity and quality of honey production and for better management of bees. This recently introduced new technology has shown significant improvement in the management of hives, bees and production of honey and wax. The beekeepers were asked whether technology/innovations are available to improve 
the production of honeybee in Tigray. Majority of the respondents (89.9 per cent) (Table 2) answered "Yes" indicating that there are technologies for improving honey production in the region. The rest of the respondents (10.1 per cent) answered "No" indicating that they did not know that technologies are available for honey bee production in Tigray. This indicates that lack of awareness on production technologies is also another concern that the regional government should address.

\begin{tabular}{|llc|}
\hline $\begin{array}{l}\text { Table 2. Response of household beekeepers to the question "are new technologies } \\
\text { introduced available to improve the production of honeybee in Tigray. }\end{array}$ \\
\hline Response & Number of respondents & Percentage \\
\hline Yes & 107 & 89.9 \\
\hline No & 12 & 10.1 \\
\hline Total & 119 & 100.00 \\
\hline
\end{tabular}

81 respondents who had adopted new technologies of bee keeping were asked, "Is there an increase in your production after you apply new technology/ innovation in honey bee keeping'? They all answered yes; there is an increase in honeybee production after applying the new technologies. Though the respondents had adopted modern methods of bee keeping, they still kept traditional beehives. They practice both traditional and modern methods of bee keeping. All the households applying the new technologies responded that there is a significance increase in their production after they apply the new method of beekeeping. However, their traditional beehives have not been completely replaced by the adoption of modern beehives. Kerealem (2005) showed that adoption rate of improved box hives is low in Ethiopia and highlighted the importance of investigating factors influencing the adoption of improved box hives. The large majority of beekeepers in the country are still producing honey using traditional hives (MoARD,

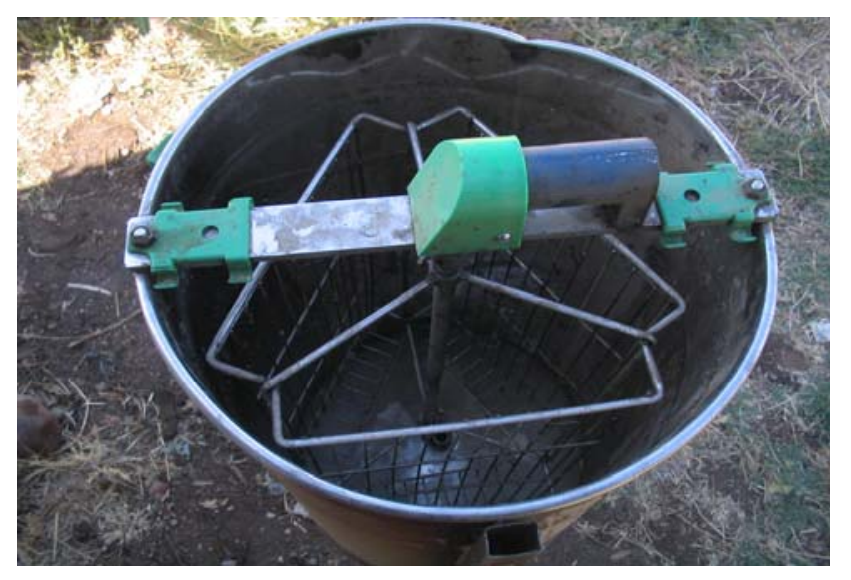

(C) CNCS
2003). Traditional methods need to be replaced by the improved and modern scientific methods for better management. Nevertheless, the use of improved modern beehives has not gained wide popularity mainly due to high cost.

Figure 2. Centrifugal honey extractor machine. 
There is a significant increase in honey production after they apply new technology. Other new technologies are also introduced including, mechanical centrifugal honey extractor (Fig. 2), casting mould, sprayer, and bee smoker. The centrifugal honey extractor machines were imported from Italy. In an attempt to reduce the cost of importing the machines, Mesfin Industrial Engineering (a local industrial engineering) is now providing the machines. However, almost all of the locally made centrifugal honey extractors are not working properly.

Of the interviewed 119 beekeepers 81 beekeepers are applying new technology to enhance honey production and increase their income, of which only 15 have been using the technology for more than 5 years and the majority (66) have been using the technology for less than 5 years (Table 3). Although beekeeping is an old age practice in the region, adoption of recently introduced technology is very low and poor. However, adoption of the new technologies is a continuous process. Bee-keeping in Tigray is practiced in an unscientific and crude way. Though new modern hive has been introduced in the region, it has not gained wide popularity due to high cost and lack of awareness.

\begin{tabular}{|lll|}
\hline \multicolumn{3}{|l|}{ Table 3. Adoption of new technology in time span in Tigray region, northern Ethiopia. } \\
\hline Years & Number of respondents & Percentage \\
\hline Less than a year & 16 & 29.6 \\
\hline $1-2$ years & 24 & 32.1 \\
\hline $2-5$ years & 26 & 18.5 \\
\hline More than 5 years & 15 & \\
\hline
\end{tabular}

\subsection{Market and honey production constraints}

Respondents were asked to state the market and technological constraints and problems associated with honey and wax production practices. According to the beekeepers, the critical constraints and problems affecting honey production in Tigray region include inadequate availability of production technologies, limited availability of bee flora mainly due to deforestation, lack of beekeeping Knowledge/skill, and marketing accessibility. Perhaps the main constraints limiting the expansion of beekeeping may be the limited flora attributed to land degradation and deforestation. Yet, there is a potential for beekeeping in the region. Sometimes training is given for those who have modern bee hives only in churches. However, farmer's access to trainings is generally poor. Other major constraint facing the sub sector is a weak 
market which led to lower contribution of honey sub sector (much lower than its potential) to the regional and national economy. The traditional beehives are not comfortable for sanitation and high level of production.

There are critical needs to introduce new movable frame hive technology to increase quantity and quality of honey production and training on apiculture farming. Modern bee-keeping is relatively expensive that requires a good financial base, which most farmers often lack. The movable frame hive is so expensive that poor beekeepers are not able to buy it. Farmers are complaining that the cost of the modern hive is so expensive; at first the cost was 350 birr, but now, it costs about 650 birr excluding the interest. This increment in cost hinders poor farmers not to buy it. All these constraints are further aggravated by inadequate extension coverage, lack of special skills and limited research works in the beekeeping sector. Inadequate vegetation coverage for bee colonies (bee forage), lack of proper bee management, and inadequate government support are other factors responsible for failure of large scale growth of apiculture in the region. Most of the rural beekeepers cannot afford to invest in inputs, process, pack, and transport their products to market to maximize profit. Moreover, lack of proper marketing channels, lack of trained development agents, poor market infrastructure are generally the major factors hampering the apiculture development in the region. Lack of appropriate production technologies, weak market and absence of value chain development largely resulted in much lower contribution of the honey sub-sector, much lower than its potential (Wilson, 2006 and Tallonitire, 2006).

If deforestation and land degradation continues, honey and beeswax production will be seriously affected. Trees that provide bee forages are being cut by the farmers to extend the agricultural fields. According to the beekeepers response, limited supply of honey due to limited availability of bee forage (due to deforestation), shortage of honey bee colonies, back ward technology, in adequate government support, high cost of improved technologies, weak market infrastructure, low quality, poor pre and post harvest management, lack of market information are current problems facing the sub sector in the region.

\subsection{Honey bee Pests and their management}

Like all living organisms honeybees can be infested with insects and infected with disease pests. Some of these pests are more deleterious to bee colonies than others, but it is important for the 
beekeepers to be able to recognize conditions which might be pest related and respond accordingly.
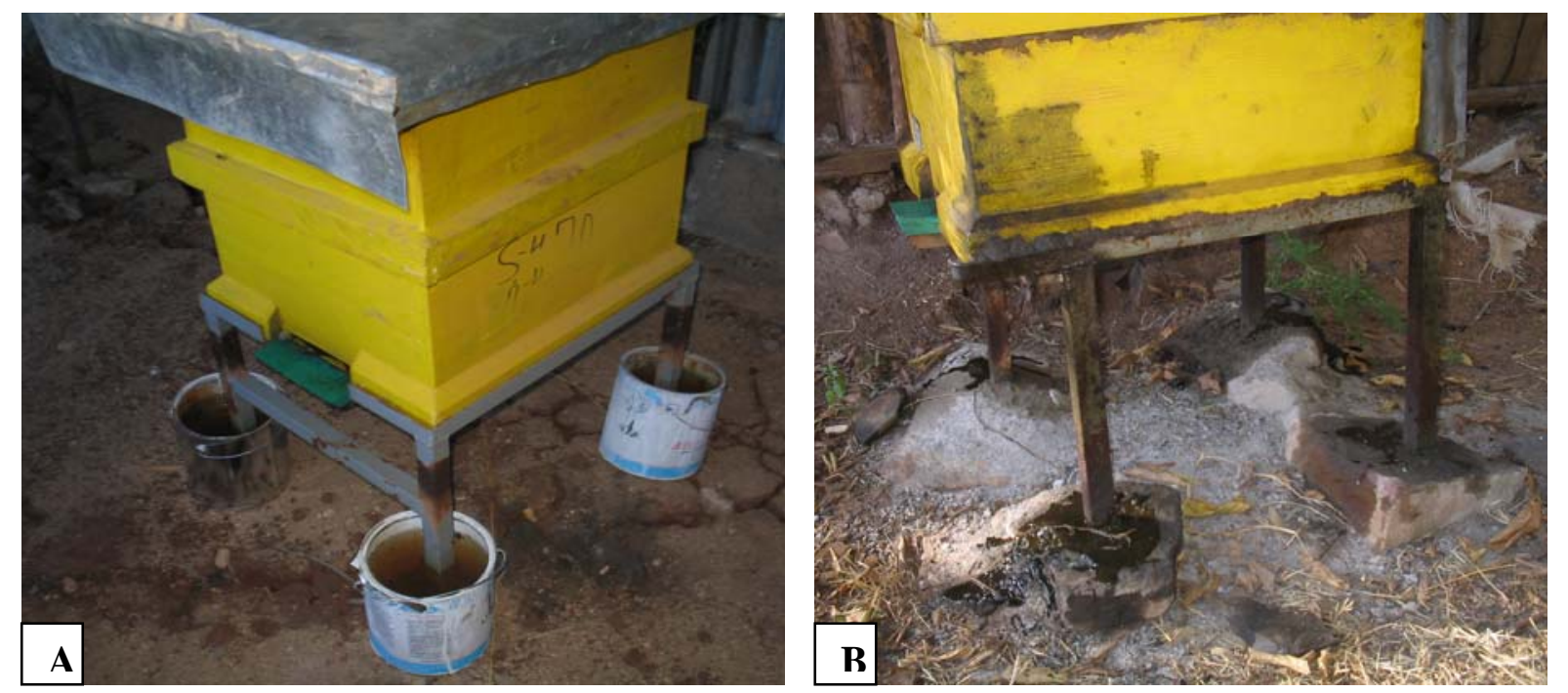

Figure 3. A. Honeybee management option designed to float pests on the water; B. Applications of Ash and dirty engine oil to protect bee pests (insect repellents).

Beekeepers were interviewed on the presence of bee pests and their control and management strategies. According to the beekeepers response there are multitudes of honey bee pests including; ants (both black and red) and ant like insects (the greatest enemies), birds, spiders and lizards. Traditionally, farmers have their own control means including the application of ash, rope around entrance of hives (hanging the predator's neck), insect repellents (such as dirty engine oil), snap and light traps, mechanical killing of the pests etc. Pests were also protected through placing the wooden top-bar beehives on a small can containing water so as to float pests on the water (Fig. 3A). However, this pest management option is suitable only for the modern beehives. All the four legs of modern beehives are also protected by insect repellents such as dirty engine oil (Fig. 3B). Each leg of the stand is placed in a shallow container full of oil. Several other insects are also protected by spreading wood ash around the stand of the beehives (Fig. 3B). Generally, as the pests are attracted to wards sweets such as honey sugar, nectar and bee's body, beekeepers should be able reduce the damage and protect the hives through the above mentioned and other related management options. 
Government should give enough attention and take beekeeping in to consideration as one of the strategies for reducing poverty and ensuring household food security. The regional government should provide regular training for beekeepers and facilitate financial services. The respondents were asked "are there agencies that helped in improving the honeybee production system in your woreda/kebele? Of the total respondents only 37.8 per cent answered "Yes" which implies there are agencies that helped the sub sector. The majority (62.2 \%) answered "No" indicating that they were not helped to increase their honeybee production and enhance their incomes. This shows that there is inadequate government support to enhance apiculture in the region. According to the bee keeper's response, REST (a local NGO) together with bureau of agriculture and natural resource development are now providing financial and technological supports to the honey sub sector. However, the support given to enhance honeybee and wax production is generally poor.

Several other insects attack honey bee colonies, including several species of ants, bee mites, bee louse (Braula coeca). In his attempt to improve his living conditions, man has caused and is still causing great damage to nature. Trees that support bee life are being destroyed. Bee populations are also declining through large scale extensive agriculture. Hence, man is perhaps the greatest pest of honeybee.

\section{CONCLUSIONS AND RECOMMENDATIONS}

We have identified the major constraints affecting honey and beeswax production in Tigray regional state, Ethiopia. These constraints include inadequate availability of production technologies, limited beekeeping Knowledge, limited availability of vegetation, limited training and technical assistance in beekeeping and honey marketing. Lack of proper bee management and marketing facilities are also problems facing the honey sub sector in the region. These constraints are further aggravated by inadequate extension coverage, lack of special skills and research undertaking in the beekeeping sector. Because of these and other related factors, the region and the rural beekeeping households have not been sufficiently benefited from the honey sub sector.

There have been a long tradition and culture of beekeeping in the region, nevertheless, productivity and production of honey bee is not developed yet. Hence, the government should give enough attention and take beekeeping into consideration as one of the strategies for 
reducing poverty and ensuring food security, and further attain MDG (Millennium Development Goals). Adequate supply of modern beehives, encouraging participation of households in beekeeping and increasing their production through planting bee plants, facilitating financial services and regular training are critically important to increase production of honey and wax on a sustainable base in the region. Adequate government support is required to increase incomes of beekeeping households. To empower the poor and promote improved honey production technologies, conservation of natural vegetation, introducing multi-purpose trees and potential bee forages should be strengthened to benefit the beekeepers. Furthermore, training and technical assistance should be given at grass root level on regular bases.

Beekeeping in Tigray is still very traditional with little intervention with modern production practices and is carried out in home gardens, in bushes, and area enclosures. The traditional beehives are made from wood, dung, and mud. Beekeeping plays a major role in socio-economic development and environmental conservation. It is a source of food (e.g. honey). It contributes to the incomes of households. A significant number of people are also engaged in trading of honey at different levels and selling of honey wines (local beverage Tej) which create job and self employment opportunities for large number of citizens.

In Tigray, deforestation, and overgrazing has nearly depleted the bee forage availability, ultimately resulting in low honey and beeswax production. However, there is still potential to increase honey production and to improve the livelihood of the beekeepers. The government also need to develop apiculture as one of the strategies to reduce poverty and ensure sustainable development. Hence, to alleviate poverty, sustain development, conserve natural resource, and secure small producers livelihood, there is a strong need to help households engaged in beekeeping thorough; trainings, research, and provision of adequate and appropriate production technologies.

\section{ACKNOWLEDGMENTS}

The authors gratefully acknowledge the support of NORAD II for funding this research. We are also very grateful to the study area communities and development agents for their very kind support throughout the study. 


\section{REFERENCES}

ARSD (Apiculture Research Strategy Document). 2000. Apiculture research strategy document. EARO (Ethiopian Agricultural Research Organization), Addis Ababa, Ethiopia.

Ayalew, K \& Gezahegn, T. 1991. Suitability Classification in Agricultural Development, Ministry of Agriculture, Addis Ababa, Ethiopia.

Berhanu, G.1998. The economics of soil conservation investments in the Tigray region of Ethiopia. Ph.D thesis, Department of Agricultural Economics: Michigan State University, East Lansing, USA, 258pp.

Beyene, T \& David, P. 2007. Ensuring small scale producers in Ethiopia to achieve sustainable and fair access to honey markets. Paper prepared for international development enterprises (IDE) and Ethiopian society for appropriate technology (ESAT), Addis Ababa, Ethiopia.

Buchmann, S. L \& Nabham, G. P. 1995. The forgotten pollinators. Island Press, Washington, DC, USA. 292pp.

Edessa, N. 2005. Survey of honey production system in West Shewa Zone. Proceeding of the 4th Ethiopian Beekeepers Association (EMA), Ethiopia.

EEPD (Ethiopian Export Promotion Development), 2006. Export of honey and beeswax. Draft report. EEPD, Ministry of Trade and Industry, Addis Ababa, Ethiopia.

Ethiopian Customs Authority and Export Promotion Agency 2006. Annual report for the year 2005.

Gezahegh, T. 2001. Apiculture Development Strategies, Ministry of Agriculture and Rural Development, Addis Ababa, Ethiopia.

Gezahegn, T. 2001. Apiculture development strategies. Ministry of Agriculture and Rural Development, Addis Ababa, Ethiopia.

Gibbon, P. 2001. Agro-Commodity Chains: An Introduction, Speech to ODI, Summer Meetings Series, http://www.odi.org.uk/speeches/gibbon.pdf

Girma, D. 1998. Non-Wood Forest Production in Ethiopia. Addis Ababa, Ethiopia. Available from: ftp://ftp. FAO. Org/decrep/fao/003/X6690E00.pdf. [Accessed on 25 September, 2007]

Hailu, A., Yohannes, G., Abera, G \& Ann Waters-Bayer. 2007. Participatory research that builds on local innovation in beekeeping to escape poverty, Rural Development News 1/2007. 
Hartmann, I. 2004. The management of resources and marginalization in beekeeping societies of South West Ethiopia. International conference on Bridge Scales and Epistemologies, Alexandria, 1.

Kerealem, E. 2005. Honeybee production system, opportunities and challenges in Enebse sar midir woreda (Amhara region) and Amaro special woreda (SNNPR), Ethiopia. MSc thesis, Alemaya University, Alemaya, Ethiopia (unpubl.).

MoARD. 2005. Annual Reports Addis Ababa, Ethiopia

Ministry of Trade and Industry. 1995. Annual external trade statistics, 1984-1994, Addis Ababa, Ethiopia.

MoARD. 2003. Honey and beeswax production and marketing plan. Amharic version. MoARD, Addis Ababa, Ethiopia.

MoARD. 2006. Annual Reports Series 2005, 2006, Addis Ababa, Ethiopia.

Nuru, A. 1999. Quality state of grading Ethiopian honey. Proceedings of the first national conference of the Ethiopian Beekeepers Association, Addis Ababa, Ethiopia.

Tallontire, A. 2006. Partnerships in Fair Trade: Reflections from a Case Study of Café direct. Development in Practice, 10: 166-77.

Wilson, R. T. 2006. Current Status and Possibilities for Improvement of Traditional Apiculture in Sub-Saharan Africa. Bartridge House, Umberleigh, UK. 